\title{
Characterization of Antibiotic Producing Rare Actinomycete Nonomuraea sp. JAJ18 Derived from an Indian Coastal Solar Saltern
}

\author{
Polpass Arul Jose, Kunjukrishnan Kamalakshi Sivakala, \\ Pandiyan Rajeswari, and Solomon Robinson David Jebakumar
}

Department of Molecular Microbiology, School of Biotechnology, Madurai Kamaraj University, Madurai 625 021, India

Correspondence should be addressed to Solomon Robinson David Jebakumar; jsolomon_mrna@yahoo.com

Received 31 July 2014; Revised 10 November 2014; Accepted 28 November 2014; Published 18 December 2014

Academic Editor: Wen-Jun Li

Copyright (C) 2014 Polpass Arul Jose et al. This is an open access article distributed under the Creative Commons Attribution License, which permits unrestricted use, distribution, and reproduction in any medium, provided the original work is properly cited.

\begin{abstract}
Rare actinomycete genera are accepted as a promising source of novel metabolites having pharmaceutical importance. One such genus of rare actinomycete is Nonomuraea. The present study was aimed at characterizing the antibiotic producing Nonomuraea strain JAJ18 which was previously isolated from coastal solar saltern. Strain JAJ18 was recognized as a member of genus Nonomuraea based on its almost complete 16S rRNA gene sequence and phenotypic characteristics. The strain JAJ18 was found to be closely related to Nonomuraea maheshkhaliensis $16-5-14^{\mathrm{T}}$ (98.90\%), Nonomuraea candida $\mathrm{HMC10} 0^{\mathrm{T}}(98.58 \%)$, and Nonomuraea jabiensis A4036 ${ }^{\mathrm{T}}$ (98.43\%). From cell-free culture broth of strain JAJ18, an antibiotic was extracted and purified by silica column chromatography. The obtained antibiotic was found to be active against a range of Gram-positive and Gram-negative bacteria including drug-resistant Staphylococcus, with minimal inhibitory concentration (MIC) ranging from 0.5 to $16.0 \mu \mathrm{g} \mathrm{mL}$. The structural characteristics of antibiotic were determined by FTIR and NMR spectroscopy. The antibiotic was identified to be an aliphatic rich compound with significant dissimilarity to known antibiotics reported from members of the genus, Nonomuraea. As the trends to discover novel metabolites from Nonomuraea are vibrant, further studies are needed to understand the structural and biotechnological significance of antibiotic compound produced by Nonomuraea sp. JAJ18.
\end{abstract}

\section{Introduction}

Enduring infectious diseases and rapidly mounting antibiotic resistance have intensified the search for new antibiotics in order to maintain a pool of effective antibiotics against the pathogenic microorganisms. In recent years, rare actinomycetes are considered as potential producers of novel bioactive compounds $[1,2]$. The rare actinomycetes that are often very difficult to isolate and cultivate might represent a unique source of novel biologically active compounds [3]. Some genera of this group are Actinomadura, Actinoalloteichus, Actinoplanes, Amycolatopsis, Actinokineospora, Acrocarpospora, Actinosynnema, Catenuloplanes, Cryptospo -rangium, Dactylosporangium, Kibdelosporangium, Kineosporia, Kutzneria, Microbispora, Microtetraspora, Nocardia, Nonomuraea, Planomonospora, Planobispora, Pseudonocardia,
Saccharomonospora, Saccharopolyspora, Saccharothrix, Salinispora, Streptosporangium, Spirilliplanes, Thermomonospora, Thermobifida, and Virgosporangium [4].

Nonomuraea is less known among the rare actinomycete genera as its taxonomic position was revised several times [5]. The genus Nonomuraea was originally proposed by Zhang et al. [6] as a member of the family Streptosporangiaceae which forms extensively branched substrate and aerial mycelia. On the basis of detailed polyphasic taxonomical analysis, the genus currently (November 2014) comprises around 36 species and 2 subspecies (http://www.bacterio.net/nonomuraea.html\#maheshkhaliensis). The members of this genus have been isolated from various soil and plant samples including mangrove rhizosphere mud [7], cave soil [8], arid soil [9], acidic soil [10], coastal sediments [11], and medicinal plants [12]. Members of genus Nonomuraea have been recognized 
as a valuable source of novel bioactive metabolites showing antimicrobial, anticancer, anthelmintic, and antipsychotic activities. To this date, some antibiotic compounds derived from different species of genus Nonomuraea are actinotiocin [13], maduramycin [14], glycopeptide antibiotic A40926 [15], and pyralomicins [16]. The trend to discover novel metabolites from the genus Nonomuraea has been augmented, which is a challenging signal for further exploration of this natural compounds producing resource [5].

The Nonomuraea sp. JAJ18 taken for this study was previously isolated from a coastal solar saltern [17], which shows antimicrobial activity against a range of bacteria. The objective of this paper was to describe strain JAJ18 to genus level based on its complete 16S rRNA gene sequence and phenotypic characteristics, purify the antibiotic from its culture broth, and disclose structural characteristics and antibacterial potential of the purified compound.

\section{Materials and Methods}

2.1. Strains and Their Maintenance. Antagonistic rare actinomycete strain, Nonomuraea sp. JAJ18, was previously isolated from a hypersaline coastal solar saltern [17]. Pure culture of this strain was maintained over modified inorganic salt agar slants which contained starch 10.0 g, yeast extract 4.0 g, NaCl $20.0 \mathrm{~g}, \mathrm{NH}_{4} \mathrm{SO}_{4} 2.0 \mathrm{~g}, \mathrm{MgSO}_{4} \cdot 7 \mathrm{H}_{2} \mathrm{O} 1.0 \mathrm{~g}, \mathrm{~K}_{2} \mathrm{HPO}_{4} 1.0 \mathrm{~g}$, and $22.0 \mathrm{~g}$ of agar in 1.0 liter of distilled water. The bacterial test strains, methicillin-resistant Staphylococcus aureus (MRSA), Bacillus subtilis MTCC 441, Klebsiella pneumonia MTCC 109, Salmonella typhi MTCC 733, and Proteus vulgaris MTCC 426, used in this study for antimicrobial assays were cultured in Mueller Hinton agar slants. The MRSA was obtained from Kovai Medical Center and Hospital, Coimbatore, India. Other bacterial strains were obtained from Microbial Type Culture Collection (MTCC), Institute of Microbial Technology, Chandigarh, India.

2.2. Colonial, Cultural, and Physiological Characterization. Cultural characteristics of JAJ18 were observed in twelve different agar media: starch casein agar [20], potato dextrose agar, glycerol nitrate agar [21], asparagine vitamin agar, sucrose nitrate agar, glucose asparagine agar [22], and series of ISP media such as yeast extract maltose agar ISP2, oatmeal agar ISP3, inorganic salt starch agar ISP4, glycerol asparagine agar ISP5, peptone yeast extract iron agar ISP 6, and tyrosine agar ISP 7 [23]. The agar plates were inoculated and incubated at $30^{\circ} \mathrm{C}$ for $7 \mathrm{~d}$. The plates were then visually examined to determine aerial spore-mass colour, substrate mycelial pigmentation, and the colour of diffusible pigments.

The growth temperature range $(15,20,25,30,37,45$, or $\left.50^{\circ} \mathrm{C}\right)$ and $\mathrm{pH}$ range $(\mathrm{pH} 4.5,5,6,6.8,7.2,9$, and 10) for the growth of strain JAJ18 were determined on modified ISP-4 after culturing for 2 weeks in shake flasks $(250 \mathrm{rpm})$ for 10 days. Salt tolerance of the actinomycete isolate JAJ18 was determined on starch nitrate medium prepared with series of $\mathrm{NaCl}$ concentrations between 0 and $30 \%$ ( 0 to $5 \mathrm{M}$ ) according to Kushner [24]. Reduction of nitrate, degradation of gelatin and casein, and production of catalase and $\mathrm{H}_{2} \mathrm{~S}$ were examined as described by Gordon et al. [25]. Utilization of a range of different sole carbon sources was tested on ISP9 medium [23].

2.3. $16 S$ rRNA Gene Amplification and Cloning. For DNA isolation, biomass was obtained by growing the strain JAJ18 in Trypticase soy broth for $7 \mathrm{~d}$ at $30^{\circ} \mathrm{C}$ with agitation in $500 \mathrm{~mL}$ flasks containing $100 \mathrm{~mL}$ of the medium. From the biomass, DNA was isolated using standard phenol-chloroform extraction procedure [26]. The $16 \mathrm{~S}$ rRNA gene was amplified from the isolated DNA using universal eubacterial primer set: $27 \mathrm{~F}$ 5' AGT TTG ATC CTG GCT CAG 3' and 1492R 5’ACG GCT ACC TTG TTA CGA CTT $3^{\prime}$ [27]. PCR amplification was carried out in a $50 \mu \mathrm{L}$ reaction mixture according to Thinesh et al. [28]. The PCR amplified 16S rRNA gene was purified using PCR product purification spin kit (HiPurA, HiMedia, India). Purified 16S rRNA gene amplicon was cloned using pGEM-T Easy vector (Promega) with E. coli DH10B cells. The plasmid DNA of the recombinant clone was isolated and sequenced by an automated sequencer (Genetic Analyzer 3130, Applied Biosystems, USA) using the vector-specific primers, SP6 and T7 promoter.

2.4. Phylogenetic Analysis. Almost complete $16 \mathrm{~S}$ rRNA gene sequences of strain JAJ18 and those of other related species derived from GenBank were aligned using ClustalW. Phylogenetic tree was inferred by using suitable programs of the PHYLIP (Phylogeny Inference Package) version 3.68. Nucleotide distances were calculated according to the algorithm of Jukes and Cantor by using DNADIST and a neighbor-joining tree was constructed using NEIGHBOR from the PHYLIP program package [29]. The robustness of tree topology was assessed by bootstrap analysis of the neighbor-joining datasets on 1000 resamplings using the SEQBOOT and CONSENSE options from the same PHYLIP package.

2.5. Production and Extraction of Antibiotic. For preparation of seed culture, spore suspensions of JAJ18 were inoculated in modified ISP- 4 broth and incubated for $3 \mathrm{~d}$ at $28^{\circ} \mathrm{C}$ on a rotary shaker $(220 \mathrm{rpm})$. A total of $2 \mathrm{~mL}$ seed culture was transferred into $200 \mathrm{~mL}$ production medium containing starch $10.0 \mathrm{~g}$, yeast extract $4.0 \mathrm{~g}, \mathrm{NaCl} 5.0 \mathrm{~g}, \mathrm{NH}_{4} \mathrm{SO}_{4} 2.0 \mathrm{~g}$, $\mathrm{MgSO}_{4} \cdot 7 \mathrm{H}_{2} \mathrm{O} 2.0 \mathrm{~g}, \mathrm{~K}_{2} \mathrm{HPO}_{4} 1.0 \mathrm{~g}, \mathrm{CaCO}_{3} 1.0 \mathrm{~g}, \mathrm{FeSO}_{4} \cdot 7 \mathrm{H}_{2} \mathrm{O}$ $0.010 \mathrm{~g}, \mathrm{ZnSO}_{4} \cdot 7 \mathrm{H}_{2} \mathrm{O} 0.001 \mathrm{~g}, \mathrm{MnCl}_{2} \cdot 4 \mathrm{H}_{2} \mathrm{O} 0.001 \mathrm{~g}$, and $\mathrm{CuSO}_{4} \cdot 5 \mathrm{H}_{2} \mathrm{O} 0.001 \mathrm{~g}$ in 1 litre of distilled water for antibiotic production. The flask was incubated for $10 \mathrm{~d}$ at $30^{\circ} \mathrm{C}$ on a rotary shaker with $220 \mathrm{rpm}$. After the incubation period, the culture broth was centrifuged at $10,000 \mathrm{rpm}$ for $10 \mathrm{~min}$ to remove the mycelial biomass. Ethyl acetate was added to the supernatants in $1: 1$ proportion and the mixture was agitated for $45 \mathrm{~min}$. The solvent layer was separated and centrifuged at $5000 \mathrm{rpm}$ for $15 \mathrm{~min}$ to remove traces of fermentation broth. The ethyl acetate fraction was evaporated and the resultant crude antibiotic was suspended in $50 \mu \mathrm{L}$ of methanol which was then checked for antibiotic activity. 
TABLE 1: Growth characteristics of strain JAJ18.

\begin{tabular}{lcccc}
\hline Agar media & Growth & Substrate mycelium & Aerial mycelium & Pigment \\
\hline ISP2 & Poor & Yellow & None & Golden yellow \\
ISP3 & Good & Brick red & White & Brick red \\
ISP4 & Good & White & Wheat & None \\
ISP5 & Good & Light wheat & None & Yellowish red \\
ISP6 & Good & Yellowish red & Wheat & None \\
ISP7 & Good & Mint cream & Dark wheat & None \\
Starch casein agar & Good & Wheat & None & None \\
Potato dextrose agar & Poor & Red & Mint cream & None \\
Glycerol nitrate agar & Good & Light yellow & Mint cream & Colorless \\
Asparagine vitamin agar & Good & Light yellow & Light wheat & None \\
Sucrose nitrate agar & Poor & Transparent & Wheat & None \\
Glucose asparagine agar & Good & & &
\end{tabular}

2.6. Purification of Antibiotic. The purification of active fraction was initiated with fractionation of crude extract by silica column chromatography using gradient solvent system (methanol: ethyl acetate gradient 10-100\%), monitored by thin layer chromatography (ethyl acetate : methanol, 9.2:0.8). The purified fractions were screened for antimicrobial activity by disc diffusion method. Mueller Hinton agar (HiMedia, India) plates were inoculated with the test microorganisms by spreading the microbial inoculums on the surface of the media. Purified fractions were loaded on $6 \mathrm{~mm}$ sterile discs, dried, and placed on the surface of the medium inoculated with test microorganism. Plates were incubated at $37^{\circ} \mathrm{C}$ for $24 \mathrm{~h}$ and observed for zone of inhibition around the discs.

2.7. Spectral Analysis of Purified Compound. Purified active compound was subjected to partial characterization using a series of spectroscopic methods like FT-IR, NMR, and MS. The FT-IR (KBr) spectrum of the compounds was recorded on Shimadzu FT/IR-8400S spectrophotometer. Band positions are reported in reciprocal centimeters $\left(\mathrm{cm}^{-1}\right)$. Interpretation of FTIR spectrum was done according to infrared frequencies described by Coates [30]. The ${ }^{1} \mathrm{H}$ and ${ }^{13} \mathrm{C} N M R$ spectra of the compounds in $\mathrm{DMSO} / \mathrm{CDCl}_{3}$ were measured at $300 \mathrm{MHz}$ and $75 \mathrm{MHz}$, respectively, on AVANCE $300 \mathrm{NMR}$ spectrometer (Bruker, USA). Tetramethylsilane (TMS) was used as internal standard for calibration of chemical shifts of ${ }^{1} \mathrm{H}$ and ${ }^{13} \mathrm{C}$ NMR spectra. Chemical shifts were reported in parts per million $(\delta)$.

2.8. Determination of Antimicrobial Potential. Purified compound with antibiotic activity was subjected to determination of minimal inhibitory concentration (MIC) and minimum bactericidal concentration (MBC) to disclose their antimicrobial potential. The MIC values were determined by microdilution broth method as per the guidelines of Clinical and Laboratory Standards Institute [31]. Minimum concentration of compound that showed $\geq 99.9 \%$ reduction of the original bacterial inoculums was determined as the MBC [32]. MIC and MBC values were compared with those of an ideal broad-spectrum antibiotic, erythromycin.

\section{Results and Discussion}

3.1. Colonial, Cultural, and Physiological Characteristics of JAJ18. The JAJ18 had pink coloured aerial mycelium and cherry red coloured substrate mycelium without diffusible pigments on modified ISP4. The growth characteristics of Nonomuraea sp. JAJ18 on twelve different agar media are summarized in Table 1. The strain JAJ18 grew well on most of the tested agar media except on sucrose nitrate agar, potato dextrose agar, and yeast extract maltose agar. Vegetative mycelium was initially white, yellow, or yellowish red on different media, and it was gradually darkened in old culture. Likewise, aerial mycelia colour was white, mint cream, or wheat colour depending on the medium. Mild diffusible yellow and brick red coloured pigments were observed in ISP2 and ISP3 agar plates, respectively.

The strain JAJ18 was studied for its range of biochemical (Table 2) and physiological (Table 3) characteristics. The strain JAJ18 utilized dextrose, cellobiose, fructose, maltose, rhamnose, salicin, sucrose, trehalose, and sodium citrate. It was negative for hydrolysis of casein and gelatin, growth in Sabouraud dextrose agar and MacConkey agar, and the reduction of nitrate. Growth of JAJ18 occurred in the range of $\mathrm{pH}(6$ to 9$)$ and temperature $\left(25\right.$ and $\left.45^{\circ} \mathrm{C}\right)$. Good growth was shown in the absence as well as in the presence of $\mathrm{NaCl}$ up to $2 \%(\mathrm{w} / \mathrm{v})$.

Phenotypic properties (growth and biochemical and physiological characteristics) of strain JAJ18 were compared with the nearest valid species Nonomuraea maheshkhaliensis 16-5-14 ${ }^{\mathrm{T}}$, Nonomuraea candida $\mathrm{HMC10}^{\mathrm{T}}$, and Nonomuraea jabiensis A $4036^{\mathrm{T}}$ (Table 4). Strain JAJ18 differs from its neighbours in its growth and pigmentation on ISP 3 medium, salt tolerance, and carbon source utilization. The JAJ18 produced brick red colour diffusible pigment on ISP3, which has not been observed in closely related strains. In the case of carbon source utilization, disparity was found in its inability to utilize inositol and mannitol.

3.2. Molecular Phylogeny of Strain JAJ18. An almost complete $16 \mathrm{~S}$ rRNA gene sequence of strain JAJ18 was obtained 
TABLE 2: Biochemical characteristics of strain JAJ18.

\begin{tabular}{|c|c|}
\hline Characteristics & Result \\
\hline \multicolumn{2}{|l|}{ Growth on } \\
\hline Sabouraud dextrose broth & - \\
\hline MacConkey agar & - \\
\hline \multicolumn{2}{|l|}{ Hydrolysis of } \\
\hline Casein & - \\
\hline Gelatin & - \\
\hline Production of $\mathrm{H}_{2} \mathrm{~S}$ & - \\
\hline Reduction of nitrate & - \\
\hline Production of catalase & + \\
\hline \multicolumn{2}{|l|}{ Utilization of } \\
\hline Adonitol & \pm \\
\hline Arabinose & \pm \\
\hline Cellobiose & + \\
\hline Dextrose & + \\
\hline Fructose & + \\
\hline Inositol & - \\
\hline Maltose & + \\
\hline Melibiose & - \\
\hline Mannose & + \\
\hline Mannitol & - \\
\hline Rhamnose & + \\
\hline Salicin & + \\
\hline Sucrose & + \\
\hline Sorbitol & - \\
\hline Xylose & \pm \\
\hline Trehalose & + \\
\hline
\end{tabular}

+: positive; \pm : doubtful/poor; -: negative.

(1484 bp) and submitted to GenBank, with accession number JN859005.2. The 16S rRNA-based phylogenetic analysis showed that strain JAJ18 was closely related to Nonomuraea maheshkhaliensis $16-5-14^{\mathrm{T}}$ (98.90\%), Nonomuraea candida $\mathrm{HMC10}^{\mathrm{T}}$ (98.58\%), Nonomuraea jabiensis A4036 ${ }^{\mathrm{T}}$ (98.43\%), Nonomuraea kuesteri GW $14-1925^{\mathrm{T}}$ (98.36\%), and Nonomuraea salmonea DSM $43678^{\mathrm{T}}$ (98.27\%). In neighbour-joining phylogenetic tree (Figure 1), strain JAJ18 formed a separate clade with Nonomuraea jabiensis $\mathrm{A} 4036^{\mathrm{T}}$.

3.3. TLC Profile of Ethyl Acetate Extract from JAJ18. Thin layer chromatograph of ethyl acetate extract of cell-free fermentation broth indicated the presence of five compounds with different $\mathrm{Rf}$ values. The chromatograph was developed using iodine vapor and visualized under UV light. The compounds were denoted as $18 \mathrm{a}, 18 \mathrm{~b}, 18 \mathrm{c}, 18 \mathrm{~d}$, and 18e which had Rf values of $0.067,0.581,0.527,0.5$, and 0.45 , respectively.

3.4. Purification of Antibiotic Produced by Nonomuraea sp. JAJ18. An antibiotic produced by Nonomuraea sp. JAJ18 was purified using the silica column monitored with TLC. Purification step yielded 13 fractions numbered from J18-1 to J18-13. All the fractions were screened for antibacterial activity against Bacillus subtilis by disc diffusion method.
TABLE 3: Physiological characteristics of strain JAJ18.

\begin{tabular}{lc}
\hline Characteristics & Result \\
\hline Growth at initial pH & \pm \\
5 & ++ \\
6 & ++ \\
6.8 & ++ \\
7.2 & + \\
9 & \\
Growth at temperature $\left({ }^{\circ} \mathrm{C}\right)$ & - \\
15 & ++ \\
25 & ++ \\
37 & + \\
45 & - \\
50 & \\
Growth in $\mathrm{NaCl}(\%)$ & ++ \\
0 & ++ \\
1 & ++ \\
2 & + \\
3 & - \\
4 & +
\end{tabular}

++: positive; +: moderate; \pm : doubtful/poor; -: negative.

Purified fraction J18-04 that showed antibiotic activity was golden yellowish in colour with a greasy appearance. Rf value of the purified fraction was found to be 0.58 in TLC. The purified antibiotic was designated as J18-04.

3.5. Spectral Characteristics of Purified Antibiotic, J18-04. Infrared spectra of J18-04 in $\mathrm{KBr}$ showed alcohol function $\left(3464.27 \mathrm{~cm}^{-1}\right), \mathrm{C}-\mathrm{H}$ stretch of saturated hydrocarbon (2985.91 and $\left.2937.68 \mathrm{~cm}^{-1}\right)$, carbonyl function $\left(1741.78 \mathrm{~cm}^{-1}\right)$, conjugated $\mathrm{C}=\mathrm{O}\left(1654.98 \mathrm{~cm}^{-1}\right)$, aliphatic nitro function $\left(1375.29 \mathrm{~cm}^{-1}\right), \mathrm{C}-\mathrm{O}$ bends $\left(1155.40-1047.38 \mathrm{~cm}^{-1}\right)$, and $=\mathrm{C}-$ $\mathrm{H}$ bends $\left(1000-650 \mathrm{~cm}^{-1}\right) .{ }^{1} \mathrm{H}-\mathrm{NMR}$ spectrum of antibiotic, $\mathrm{J} 18-04$, in $\mathrm{DMSO} / \mathrm{CDCl}_{3}$ exhibited signals at $\delta \mathrm{H} 1.99,2.15$, $2.18,2.20,2.50,5.35,5.76,7.24,7.27,7.36,7.38,7.41$, and 7.69. The signals shown in the $0.5-2$ and $2-2.5$ regions indicate the presence of alkyl protons. Similarly, signals at 5.35 and 5.75 clearly showed presence of alkenes. ${ }^{13} \mathrm{C}$-NMR spectrum of J18-04 exhibited some common main signals at $\delta \mathrm{C} \mathrm{13.76,}$ $18.77,22.04,22.40,28.50,28.95,29.06,31.22$, 33.64, and 174.33. The signals between 13.76 and 33.64 indicate carbons of methyl and methylene moieties. The signal at 174.33 indicates the presence of carbonyl carbon.

The spectral data confirmed that purified compound contains more aliphatic units and range of functional moieties such as carbonyl function, aliphatic nitro function, and aliphatic halogen groups. It shared significant dissimilarity with the structural nature antibiotics such as actinotiocin 1500 [13], maduramycin 937 [14], glycopeptide antibiotic A40926 1300 [15], and pyralomicins derived from genus Nonomuraea. However, deeper studies will be needed to establish chemical structure of this active compound. 
TABlE 4: Comparison of the phenotypic properties of Nonomuraea sp. JAJ18 with Nonomuraea maheshkhaliensis $16-5-14^{\mathrm{T}}$, Nonomuraea candida $\mathrm{HMCl0}^{\mathrm{T}}$, and Nonomuraea jabiensis $\mathrm{A} 4036^{\mathrm{T}}$.

\begin{tabular}{|c|c|c|c|c|}
\hline Characteristics & JAJ18 & $\mathrm{HMC10}^{\mathrm{T}}[18]$ & $16-5-14^{\mathrm{T}}[7]$ & $\mathrm{A} 4036^{\mathrm{T}}[19]$ \\
\hline \multicolumn{5}{|l|}{ Growth on ISP 3 medium } \\
\hline Aerial mycelium & White & White & White & None \\
\hline Substrate mycelium & Orange/red & Cream & Light wheat & Brownish orange \\
\hline \multicolumn{5}{|c|}{ Growth on sole carbon sources $(1 \%, \mathrm{w} / \mathrm{v})$} \\
\hline Adonitol & \pm & ND & ND & + \\
\hline Arabinose & \pm & \pm & + & ND \\
\hline Cellobiose & + & \pm & + & - \\
\hline Dextrose & + & ND & + & ND \\
\hline Fructose & + & + & + & + \\
\hline Inositol & - & + & \pm & ND \\
\hline Maltose & + & ND & ND & + \\
\hline Mannose & + & + & + & + \\
\hline Mannitol & - & ND & + & + \\
\hline Rhamnose & + & + & + & $\mathrm{ND}$ \\
\hline Sucrose & + & + & + & + \\
\hline Sorbitol & - & ND & ND & - \\
\hline Xylose & \pm & + & + & + \\
\hline Growth temperature range & $23-37^{\circ} \mathrm{C}$ & $30-45^{\circ} \mathrm{C}$ & $20-37^{\circ} \mathrm{C}$ & $20-37^{\circ} \mathrm{C}$ \\
\hline Growth at $3 \% \mathrm{NaCl}$ & - & + & + & - \\
\hline
\end{tabular}

+: positive; \pm : doubtful/weak; -: negative; ND: not determined.

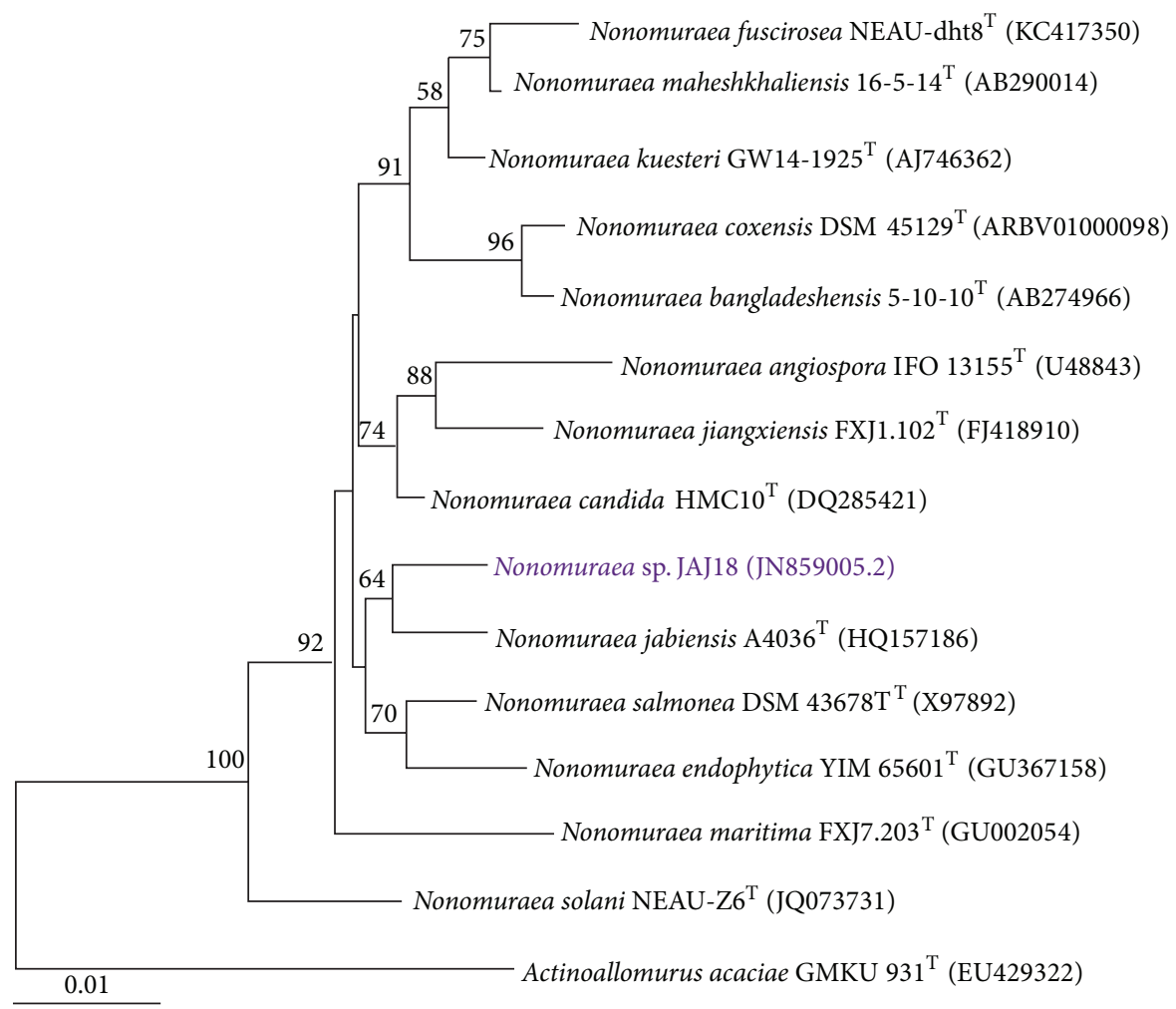

FIGURE 1: Neighbour-joining tree based on almost complete 16S rRNA gene sequences of JAJ18. The phylogenetic tree shows the relationships between Nonomuraea sp. JAJ18 and members of the genus Nonomuraea. Actinoallomurus acacia GMKU $931^{\mathrm{T}}$ was used as out-group. Numbers at nodes indicate the levels of bootstrap support (\%) based on a neighbour-joining analysis of 1000 resampled datasets. Score bar represents 1 nucleotide substitution per 100 nucleotides. 
TABLE 5: Antimicrobial potential of antibiotic, J18-04, against different bacteria.

\begin{tabular}{lcc}
\hline \multirow{2}{*}{ Test organisms } & \multicolumn{2}{c}{ MIC $(\mathrm{MBC})^{*}\left(\mu \mathrm{g} \mathrm{mL} \mathrm{mL}^{-1}\right)$} \\
& Compound & Erythromycin \\
\hline Bacillus subtilis MTCC 441 & 0.5 to $2(>2)$ & 0.5 to $1(>2)$ \\
Klebsiella pneumoniae MTCC 109 & 4 to 8 & 2 to 3 \\
MRSA (clinical strain) & 4 to $16(>16)$ & $>128(>134)$ \\
Salmonella typhi MTCC 733 & 2 to $3(>4)$ & 2 to $4(>4)$ \\
Proteus vulgaris MTCC 426 & 2 to $4(>4)$ & 1 to $4(>2)$ \\
\hline
\end{tabular}

${ }^{*}$ Values in the parenthesis are MBCs.

3.6. In Vitro Antimicrobial Potential of J18-04. The in vitro antimicrobial potential of the purified antibiotic from JAJ18 was evaluated against a list of bacteria. The compound J18-04 showed potent inhibitory activity against both of the Grampositive and Gram-negative bacteria (Table 5). The minimal inhibitory concentrations (MICs) of J18-04 observed for tested bacterial strains were in the range between 0.5 and $16 \mu \mathrm{g} \mathrm{mL}^{-1}$. Similarly, MBC values were in the range between 2 and $>16 \mu \mathrm{g} \mathrm{mL}^{-1}$. Moreover, it was found to be comparable with MICs and MBCs of the broad-spectrum antibiotic, erythromycin.

\section{Conclusion}

In summary, the strain JAJ18 was characterized to be a member of rare actinomycete genus Nonomuraea and was designated as Nonomuraea sp. JAJ18. It is clear that the Nonomuraea sp. JAJ18 produces extracellular antibiotic which is effective against a range of bacterial strains including MRSA. The antibiotic purified from Nonomuraea sp. JAJ18 was designated as J18-04. Spectral characteristics of purified compound showed presence of a range of functional moieties dissimilar to previously reported antibiotics of Nonomuraea species. The results reveal the importance and need of complete structural and in vitro pharmacological studies to uncover the industrial importance of identified antibiotic, J18-04.

\section{Conflict of Interests}

The authors declare that there is no conflict of interests regarding the publication of this paper.

\section{Acknowledgment}

The authors acknowledge the financial supports from the Council of Scientific and Industrial Research-Human Resource Development Group (CSIR-HRDG), India, for the funding through Senior Research Fellowship.

\section{References}

[1] K. Tiwari and R. K. Gupta, "Rare actinomycetes: a potential storehouse for novel antibiotics," Critical Reviews in Biotechnology, vol. 32, no. 2, pp. 108-132, 2012.
[2] P. A. Jose and S. R. D. Jebakumar, "Non-streptomycete actinomycetes nourish the current microbial antibiotic drug discovery," Frontiers in Microbiology, vol. 4, article 240, 2013.

[3] R. H. Baltz, "Marcel Faber Roundtable: is our antibiotic pipeline unproductive because of starvation, constipation or lack of inspiration?" Journal of Industrial Microbiology and Biotechnology, vol. 33, no. 7, pp. 507-513, 2006.

[4] K. Tiwari and R. K. Gupta, "Diversity and isolation of rare actinomycetes: an overview," Critical Reviews in Microbiology, vol. 39, no. 3, pp. 256-294, 2013.

[5] R. Sungthong and N. Nakaew, "The genus Nonomuraea: a review of a rare actinomycete taxon for novel metabolites," Journal of Basic Microbiology, 2014.

[6] Z. Zhang, Y. Wang, and J. Ruan, "Reclassification of Thermomonospora and Microtetraspora," International Journal of Systematic Bacteriology, vol. 48, no. 2, pp. 411-422, 1998.

[7] I. Ara, T. Kudo, A. Matsumoto, Y. Takahashi, and S. Omura, "Nonomuraea maheshkhaliensis sp. nov., a novel actinomycete isolated from mangrove rhizosphere mud," Journal of General and Applied Microbiology, vol. 53, no. 3, pp. 159-166, 2007.

[8] N. Nakaew, R. Sungthong, A. Yokota, and S. Lumyong, "Nonomuraea monospora sp. nov., an actinomycete isolated from cave soil in Thailand, and emended description of the genus Nonomuraea," International Journal of Systematic and Evolutionary Microbiology, vol. 62, no. 12, pp. 3007-3012, 2012.

[9] M. Camas, A. Sazak, C. Spröer et al., "Nonomuraea jabiensis sp. nov., isolated from arid soil," International Journal of Systematic and Evolutionary Microbiology, vol. 63, no. 1, pp. 212-218, 2013.

[10] X. Li, L. Zhang, Y. Ding, Y. Gao, J. Ruan, and Y. Huang, "Nonomuraea jiangxiensis sp. nov., isolated from acidic soil," International Journal of Systematic and Evolutionary Microbiology, vol. 62, no. 6, pp. 1409-1413, 2012.

[11] L. Xi, L. Zhang, J. Ruan, and Y. Huang, "Nonomuraea maritima sp. nov., isolated from coastal sediment," International Journal of Systematic and Evolutionary Microbiology, vol. 61, no. 11, pp. 2740-2744, 2011.

[12] J. Li, G.-Z. Zhao, H.-Y. Huang et al., "Nonomuraea endophytica sp. nov., an endophytic actinomycete isolated from Artemisia annua L," International Journal of Systematic and Evolutionary Microbiology, vol. 61, no. 4, pp. 757-761, 2011.

[13] A. Tamura, R. Furuta, S. Naruto, and H. Ishii, "Actinotiocin, a new sulfur containing peptide antibiotic from Actinomadura pusilla," The Journal of Antibiotics, vol. 26, no. 6, pp. 343-350, 1973.

[14] W. F. Fleck, D. G. Strauss, J. Meyer, and G. Porstendorfer, "Fermentation, isolation, and biological activity of maduramycin: a new antibiotic from Actinomadura rubra," Zeitschrift fur Allgemeine Mikrobiologie, vol. 18, no. 6, pp. 389-398, 1978.

[15] N. Gunnarsson, P. Bruheim, and J. Nielsen, "Production of the glycopeptide antibiotic A40926 by Nonomuraea sp. ATCC 39727: influence of medium composition in batch fermentation," Journal of Industrial Microbiology and Biotechnology, vol. 30, no. 3, pp. 150-156, 2003.

[16] P. M. Flatt, X. Wu, S. Perry, and T. Mahmud, "Genetic insights into pyralomicin biosynthesis in Nonomuraea spiralis IMC A0156," Journal of Natural Products, vol. 76, no. 5, pp. 939-946, 2013.

[17] P. A. Jose and S. R. D. Jebakumar, "Phylogenetic diversity of actinomycetes cultured from coastal multipond solar saltern in Tuticorin, India," Aquatic Biosystems, vol. 8, no. 13, article 23, 2012. 
[18] M. le Roes and P. R. Meyers, "Nonomuraea candida sp. nov., a new species from South African soil," Antonie van Leeuwenhoek, vol. 93, no. 1-2, pp. 133-139, 2008.

[19] M. Camas, A. Sazak, C. Spröer et al., "Nonomuraea jabiensis sp. nov., isolated from arid soil," International Journal of Systematic and Evolutionary Microbiology, vol. 63, no. 1, pp. 212-218, 2013.

[20] E. M. H. Wellington and T. Cross, "Taxonomy of antibiotic producing Actinomycetes and new approaches to their selective isolation," in Progress in Industrial Microbiology, M. E. Bushell, Ed., Elsevier, Amsterdam, The Netherlands, 1983.

[21] Y. Okami, S. Arima, and M. Suzuki, "Influence of agar on the morphology and pigmentation of Streptomycetes," Applied and Environmental Microbiology, vol. 11, pp. 493-497, 1963.

[22] R. E. Gordon and M. M. Smith, "Proposed group of characters for the separation of Streptomyces and Nocardia," Journal of Bacteriology, vol. 69, no. 2, pp. 147-150, 1955.

[23] E. B. Shirling and D. Gottlieb, "Methods for characterization of Streptomyces species," International Journal of Systematic Bacteriology, vol. 16, pp. 313-340, 1966.

[24] D. J. Kushner, "Growth and nutrition of halophilic bacteria," in The Biology of Halophilic Bacteria, R. H. Vreeland and L. I. Hochstein, Eds., pp. 87-104, CRC Press, Boca Raton, Fla, USA, 1993.

[25] R. E. Gordon, D. A. Barnett, J. E. Handerhan, and C. Hor Nay Pang, "Nocardia coeliaca, Nocardia autotrophica, and the nocardin strain," International Journal of Systematic Bacteriology, vol. 24, no. 1, pp. 54-63, 1974.

[26] D. A. Hopwood, M. J. Bibb, K. F. Chater et al., Genetic Manipulation of Streptomyces: A Laboratory Manual, The John Innes Foundation, Norwich, UK, 1985.

[27] D. J. Lane, "16S/23S rRNA sequencing," in Nucleic acid Techniques in Bacterial Systematic, E. Stackebrandt and M. Goodfellow, Eds., pp. 115-175, John Wiley \& Sons, New York, NY, USA, 1991.

[28] T. Thinesh, P. A. Jose, and E. J. K. Patterson, "Predominant bacterial candidates associated with diseased corals from Gulf of Mannar, India," Journal of Pure and Applied Microbiology, vol. 7, no. 3, pp. 2397-2403, 2013.

[29] J. Felsenstein, PHYLIP (Phylogeny Inference Package) Version 3.68, Department of Genome Sciences, University of Washington, Seattle, Wash, USA, 2008.

[30] J. Coates, "Interpretation of infrared spectra, a practical approach," in Encyclopedia of Analytical Chemistry, R. A. Meyers, Ed., pp. 10815-10837, John Wiley \& Sons, Chichester, UK, 2000.

[31] NCCLS, Methods for Antimicrobial Susceptibility Testing of Anaerobic Bacteria; Approved Standard, NCCLS document M11A5, National Committee for Clinical Laboratory Standards, Wayne, Pa, USA, 5th edition, 2001.

[32] G. M. Eliopoulus and R. C. J. Moellering, "Antimicrobial combinations," in Antibiotics in Laboratory Medicine, V. Lorian, Ed., pp. 52-111, Williams \& Wilkins, Baltimore, Md, USA, 1996. 

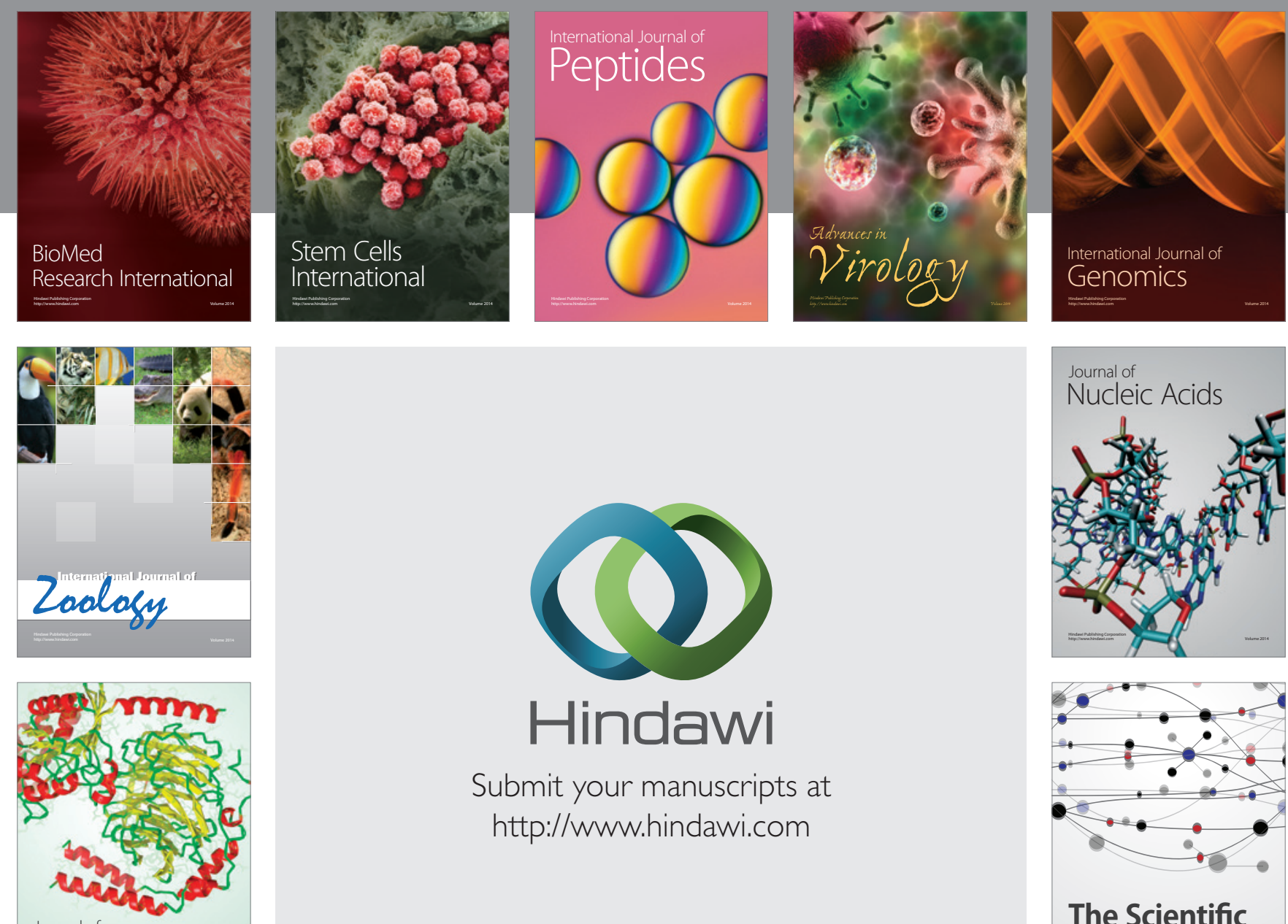

Submit your manuscripts at

http://www.hindawi.com

Journal of
Signal Transduction
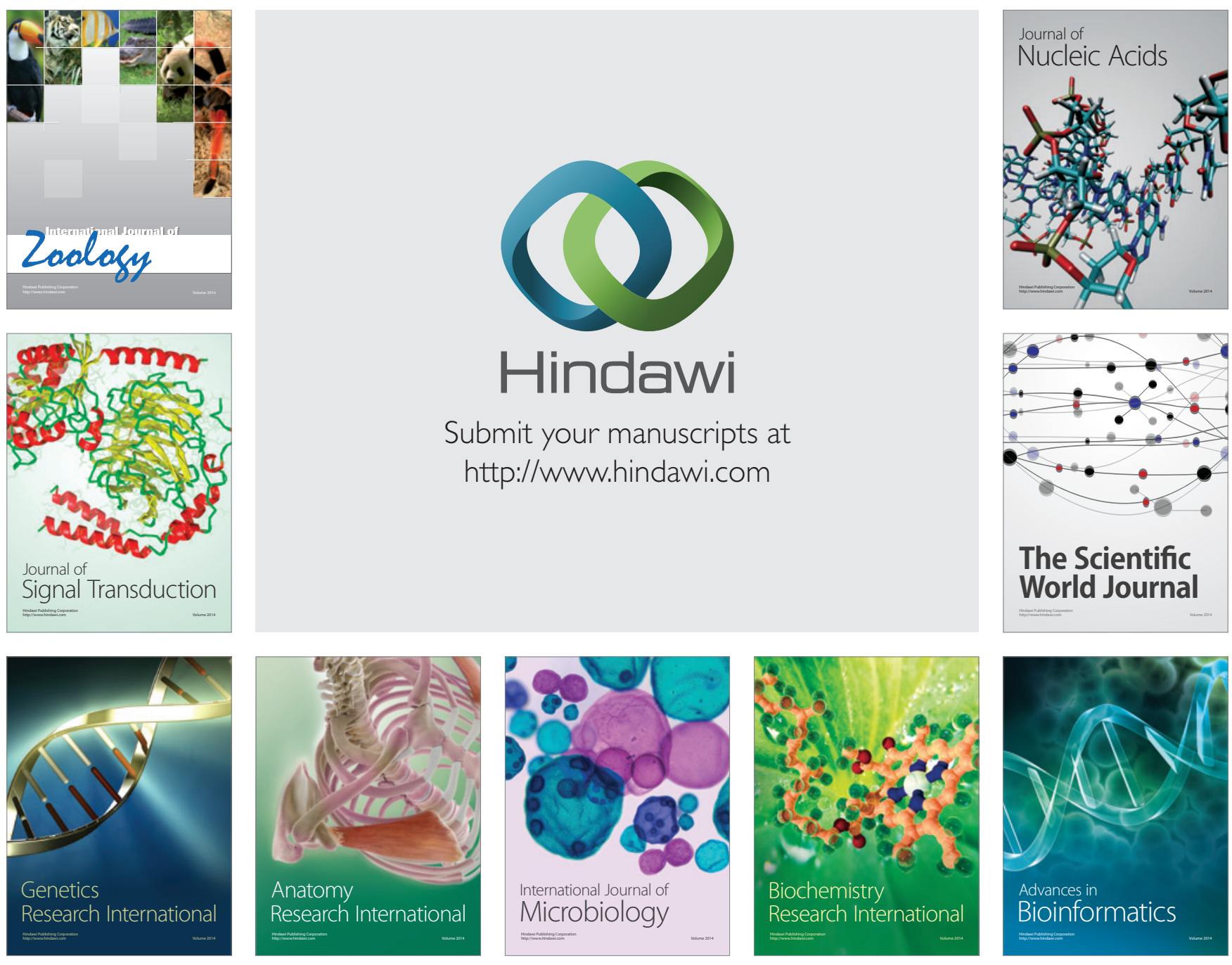

The Scientific World Journal
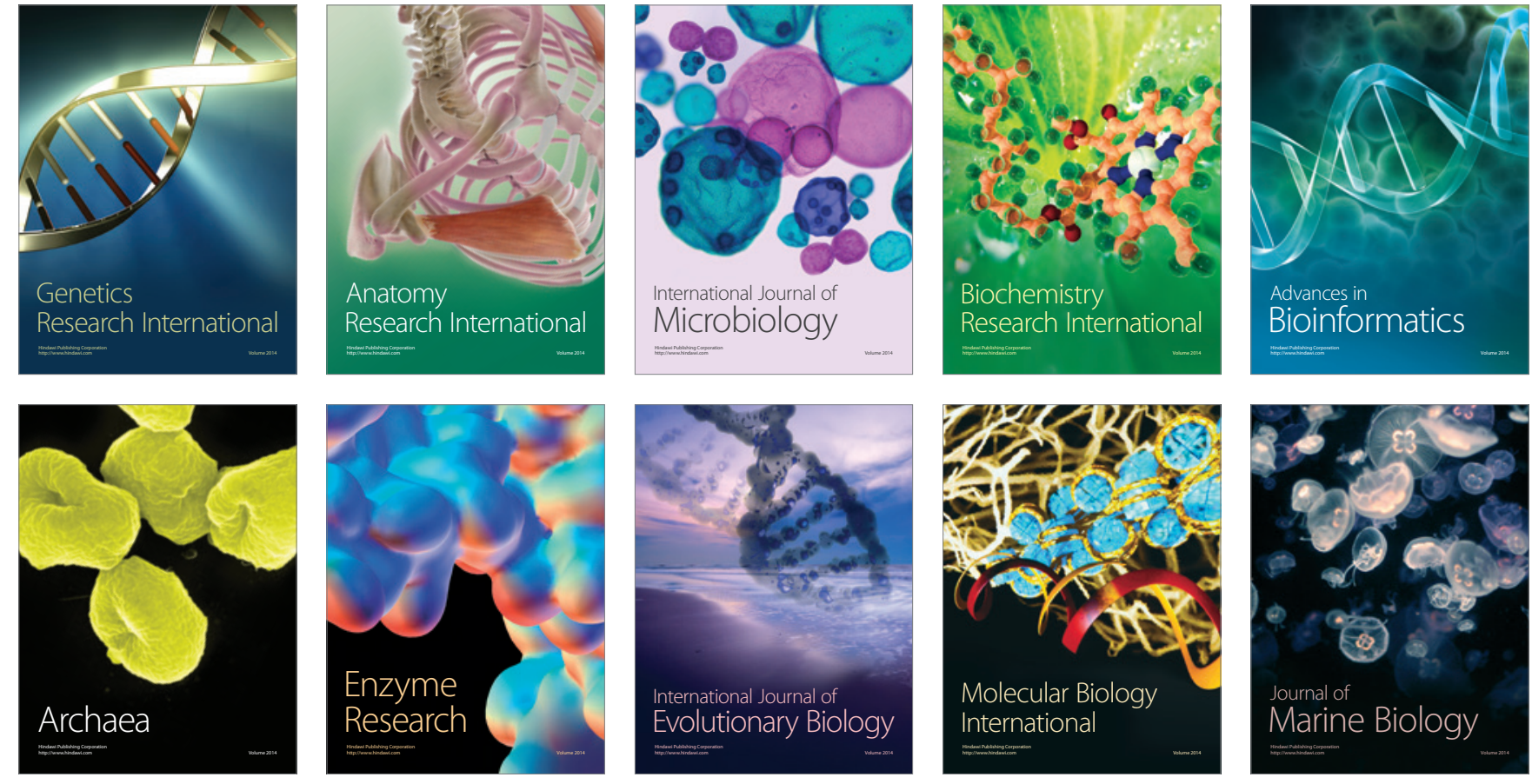